\title{
Performance evaluation and application of new fuzzy-ball micro bubble treatment fluid
}

\author{
Huaizhu Liu ${ }^{1}$ LiangChuan $\mathrm{Li}^{1} \cdot$ Jiapeng Zheng ${ }^{1}$
}

Received: 8 November 2013/ Accepted: 17 May 2015/Published online: 5 June 2015

(c) The Author(s) 2015. This article is published with open access at Springerlink.com

\begin{abstract}
It is easy to pollute formation using the conventional method of plug channeling when the oil well cement quality is bad. To solve the problem of formation pollution, one new oil layer diverting agent-micro bubble treatment fluid is developed. It cannot reverse rock wettability and cannot stop reservoir fluid flowing. The properties of rheology, static plugging, and dynamic pollution of micro bubble treatment fluid were evaluated. The laboratory experiment proved that the fuzzy-ball micro bubble treatment fluid has good injectability and its viscosity decrease with shear rate. Under the temperature of $120^{\circ} \mathrm{C}$, back pressure of $0.5 \mathrm{MPa}$ and differential pressure of $5 \mathrm{MPa}$, the leakage of micro bubble was zero. Core permeability recovered ratio was up to $96.1 \%$ after pollution for $48 \mathrm{~h}$. The new fluid has been used on four wells in Jidong Oilfield. The results of pilot test showed that the effect of decreasing produced water and increasing oil production was very obvious. The cumulative quantity of oil was $12,435 \mathrm{t}$; the cumulative decreased quantity of water was 32,496 cubic meters and the average water cut had decreased by $17.6 \%$. The application effect indicates that it not only can reduce the operating risk but also has good plug channeling and layer protecting effect. After it is used on spot, the effect of increasing oil production and reducing aquifer yield is obvious, and the period of validity is longer.
\end{abstract}

Huaizhu Liu

liuhuaizhu007@126.com

1 Drilling \& Production Technology Research Institute of Jidong Oilfield, Tangshan, China
Keywords Fuzzy-ball - Micro bubble treatment fluid . Oil layer protection · Plug channeling

\section{Introduction of the new treatment fluid}

Oilfield produced water is a common problem which brings serious damage on oil well production, and oil and gas gathering system under the process of oilfield development (Hernandez et al. 2010; Abbasy et al. 2008; Eoff et al. 2007; Seright and Liang 1994). To solve this problem, squeezing cement to plug channeling is one conventional way. This way has advantages of lower construction cost and short construction time. But it is easy to pollute formation especially high porosity and permeability formation, and reduce oil production (Mercado et al. (2009); Van Eijden et al. 2004; Lane and Sanders 1995; Van Eijden et al. 2005). To make the damage reduced to an absolute minimum, new treatment fluid must be developed. After a large amount of testing work, new fuzzy-ball micro bubble treatment fluid is developed.

\section{Preparation of the new fuzzy-ball micro bubble treatment fluid}

Under laboratory conditions, add $0.25 \mathrm{~g}$ polyanionic cellulose, $3.5 \mathrm{~g}$ hydroxyethyl starch, $0.3 \mathrm{~g}$ sodium dodecyl benzene sulfonate and $0.5 \mathrm{~g}$ sodium dodecyl sulfate into water whose volume is $100 \mathrm{~mL}$. Stir the solution for 20 min with step-less high-speed mixer under the speed of $10,000 \mathrm{r} / \mathrm{min}$, then the new fuzzy-ball micro bubble treatment fluid is fully prepared. Its density is $0.85 \mathrm{~g} / \mathrm{cm}^{3}$, dynamic shear force is $15.5 \mathrm{~Pa}$, initial gel strength is $4 \mathrm{~Pa}$, terminal gel strength is $5 \mathrm{~Pa}$ and extreme pressure lubrication coefficient is 0.054 .

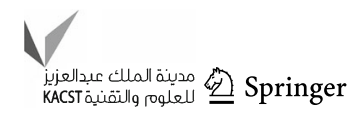




\section{Structure of the new fuzzy-ball micro bubble treatment fluid}

Use microscope of type SY100 to zoom in fuzzy-ball structure from 1000 to 3000 times, and take a photograph for observation (Fig. 1).

The center of spherical fuzzy-ball is wrapped by gas which is called gas core. There is surfactant film which is called surface tension reducing membrane outside of gas core, and it can reduce the gas-liquid interfacial tension and make the gas core accumulate energy. There is water layer outside of surface tension reducing membrane which is formed by hydration and association of surfactant hydrophilic end, it is called high viscosity layer because its viscosity is much higher than the continuous phase. There is surfactant membrane outside of the high viscosity layer which can keep the viscosity of water layer high and is called high viscosity layer fixing membrane. The membrane outside high viscosity layer fixing membrane which is called compatibility enhancing membrane is formed because of the adsorption of surfactant lipophilic group. It is composed of polymer and surfactant outside of compatibility enhancing membrane. Because of the concentration of continuous phase gradually reducing, the loose layer which is called concentration transition layer of polymer and surfactant is formed.

The gas bag is composed of gas core, surface tension reducing membrane, high viscosity layer and high viscosity layer fixing membrane. The strength of gas bag increases under the support of high viscosity layer. There is fuzzyball under the interaction between compatibility enhancing membrane and concentration transition layer of polymer and surfactant. The binding force between the fuzzy-ball and gas bag is so weak that the fuzzy-ball can depart from the gas bag and go into the continuous phase on the

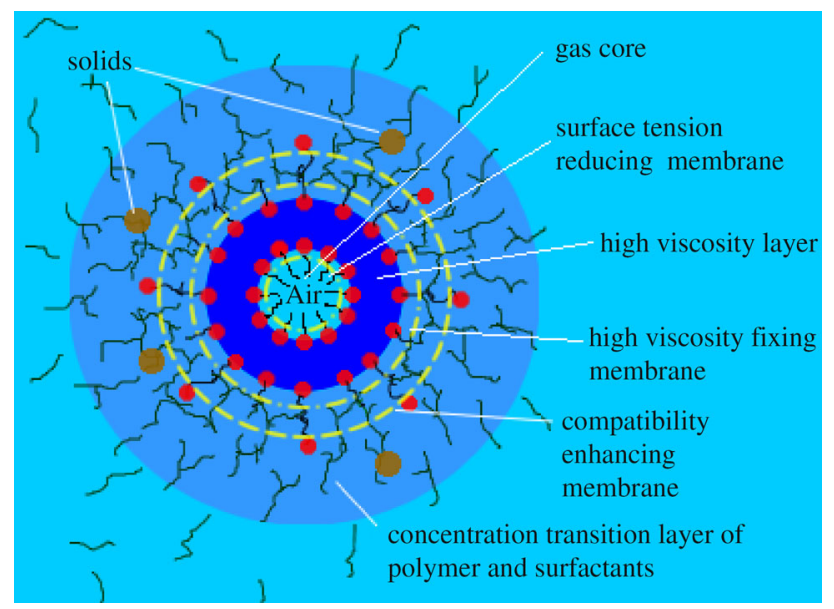

Fig. 1 The structure of fuzzy-ball micro bubble treatment fluid condition of shearing action. Because of gas bag and fuzzyball combination and separation in different environments, the new treatment fluid has unique strong shear thinning and blocking feature.

\section{Experiment}

\section{Experimental instruments}

The experimental instruments are composed of tranquil flow pump, loss circulation analog device, rheometer (M7400), vacuum saturation device, constant temperature box and high-pressure vessel.

\section{Plug channeling with cement experiment}

Put quartz sand whose diameter is, respectively, 0.2, $0.3 \mathrm{~mm}$ into two sand-packed tubes. The two sand pipes are connected in parallel. Drive water into the two sandpacked tubes at the rate of $1 \mathrm{ml} / \mathrm{min}$ and measure their water permeability. Connect intermediate container which is full of cement with sand-packed tubes. At last, drive cement into the two sand-packed tubes at the rate of $1 \mathrm{ml} /$ min and measure their water permeability.

\section{Statistic loss circulation experiment}

Mix quartz sand whose diameter is, respectively, 0.2, 0.25, $0.3 \mathrm{~mm}$ according to the ratio of $6: 2: 2$. Then, fill loss circulation analog device with the mixed quartz sand. Drive water into sand-packed tube at the rate of $1 \mathrm{ml} / \mathrm{min}$ and measure its water permeability. Fill loss circulation analog device with micro bubble treatment fluid. Back pressure of $0.5 \mathrm{MPa}$ is applied to the device and record the amount of leakage under the conditions of different differential pressure.

\section{Dynamic pollution experiment}

The diameter of core is $25.3 \mathrm{~mm}$ and its length is $76.5 \mathrm{~mm}$. Experimental procedure is as follows: First, measure its oil permeability and put it in core holder. Second, annulus pressure of $2 \mathrm{MPa}$ is applied on core holder. Third, connect intermediate container which is full of micro bubble treatment fluid with core holder. Four, put them in constant temperature box whose temperature is $120{ }^{\circ} \mathrm{C}$. Five, drive micro bubble treatment fluid into core at the rate of $1 \mathrm{ml} /$ min until the fluid is run out. Six, maintain the core in constant temperature box for $48 \mathrm{~h}$. Seven, drive water into core at the rate of $1 \mathrm{ml} / \mathrm{min}$ and record the permeability of core. 


\section{Result and discussion}

\section{Rheological properties}

It is shown that apparent viscosity decreases with the increase of shear rate in Fig. 2 and the fluid has strong shear thinning ability. Its apparent viscosity is only $57.63 \mathrm{mPa} \mathrm{s}$ under the shear rate of $400 \mathrm{~s}^{-1}$. The micro bubble treatment fluid has good injection performance.

\section{Plug channeling with cement experiment}

It is shown that the plugging ratio of main aquifer layer is $99.9 \%$. The main aquifer layer is blocked when the cement is injected. But the plugging ratio of main production layer is up to $87.2 \%$ in Table 1 and most of the layer is polluted which makes the main production layer play little role on exploration and production of oil well.

\section{Statistic loss circulation experiment}

Take the sand column out of the sand filling tube. It is found that there is a dense smooth thin filter cake in Fig. 3. Micro bubble treatment fluid is filled in the central sand column, and the lower sand is still dry. It is shown that there is no leakage under back pressure of $0.5 \mathrm{MPa}$ when differential pressure increased from 1 to $5 \mathrm{MPa}$ in Table 2 . It is demonstrated that blocking capability of micro bubble treatment fluid is strong.

\section{Dynamic pollution experiment}

From experiment result, the inital permeability is $1.8 \mu \mathrm{m}^{2}$, it is found that value of core permeability is $0.5 \mu \mathrm{m}^{2}$ and its recovered ratio is $27.8 \%$ after $20 \mathrm{~min}$. One hour later, it increases to $88.9 \%$. It is demonstrated that micro bubble treatment fluid has lower damage to formation and has good flow back capacity (Fig. 4).

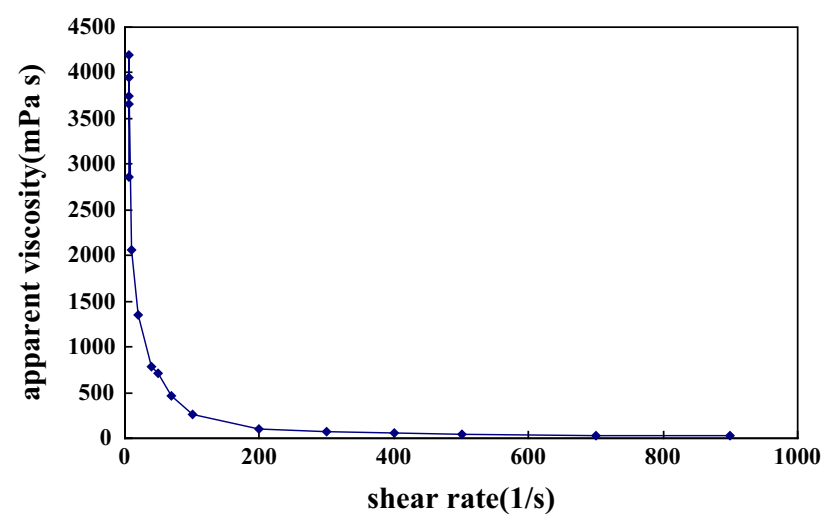

Fig. 2 Relationship of apparent viscosity and shear rate
Table 1 Results of plug channeling with cement experiment

\begin{tabular}{llll}
\hline Type & \multicolumn{2}{l}{ Water permeability $\left(10^{-3} \mu \mathrm{m}^{2}\right)$} & Plugging ratio (\%) \\
\cline { 2 - 3 } & $\begin{array}{l}\text { Before cement } \\
\text { injection }\end{array}$ & $\begin{array}{l}\text { After cement } \\
\text { injection }\end{array}$ & \\
\hline H-1 & 1124 & 1.29 & 99.9 \\
L-1 & 678 & 86.95 & 87.2 \\
\hline
\end{tabular}

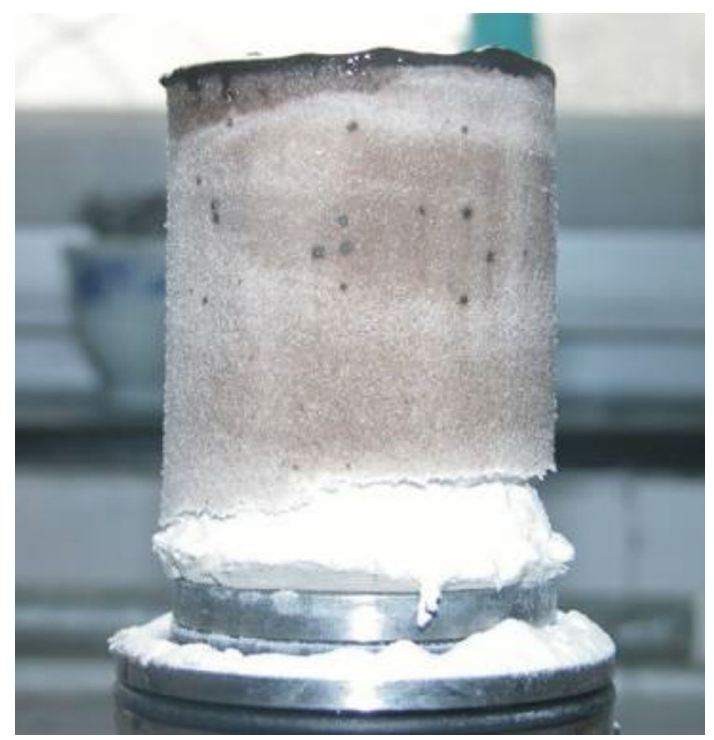

Fig. 3 Fuzzy-ball micro bubble treatment fluid plugging sand compound

Table 2 Results of micro bubble static plugging experiment

\begin{tabular}{llllll}
\hline $\begin{array}{l}\text { Temperature } \\
\left({ }^{\circ} \mathrm{C}\right)\end{array}$ & $\begin{array}{l}\text { Height of } \\
\text { sand filled } \\
(\mathrm{cm})\end{array}$ & $\begin{array}{l}\text { Back } \\
\text { pressure } \\
(\mathrm{MPa})\end{array}$ & $\begin{array}{l}\text { Differential } \\
\text { pressure } \\
(\mathrm{MPa})\end{array}$ & $\begin{array}{l}\text { Time } \\
(\mathrm{min})\end{array}$ & $\begin{array}{l}\text { Volume } \\
\text { of } \\
\text { leakage } \\
(\mathrm{ml})\end{array}$ \\
\hline 120 & 9 & 0.5 & 1 & 30 & 0 \\
120 & 9 & 0.5 & 2 & 30 & 0 \\
120 & 9 & 0.5 & 3 & 30 & 0 \\
120 & 9 & 0.5 & 4 & 30 & 0 \\
120 & 9 & 0.5 & 5 & 30 & 0 \\
\hline
\end{tabular}

\section{Pilot test and effect analysis}

Lithological mineral of production layer in Jidong Oilfield is mainly composed of fine sandstone. Its average porosity is about $25 \%$, and its permeability is $288-5310 \times 10^{-3}$ $\mu \mathrm{m}^{2}$. Because of bad cement quality, there is water channeling between oil layer and water layer during the process of oilfield development. This phenomenon caused a serious impact on the development of oil wells. For solving this problem, the new micro bubble treatment fluid is used in four oil wells. The cumulative injected volume of the new 
Fig. 4 Result of micro bubble treatment fluid dynamic pollution experiment

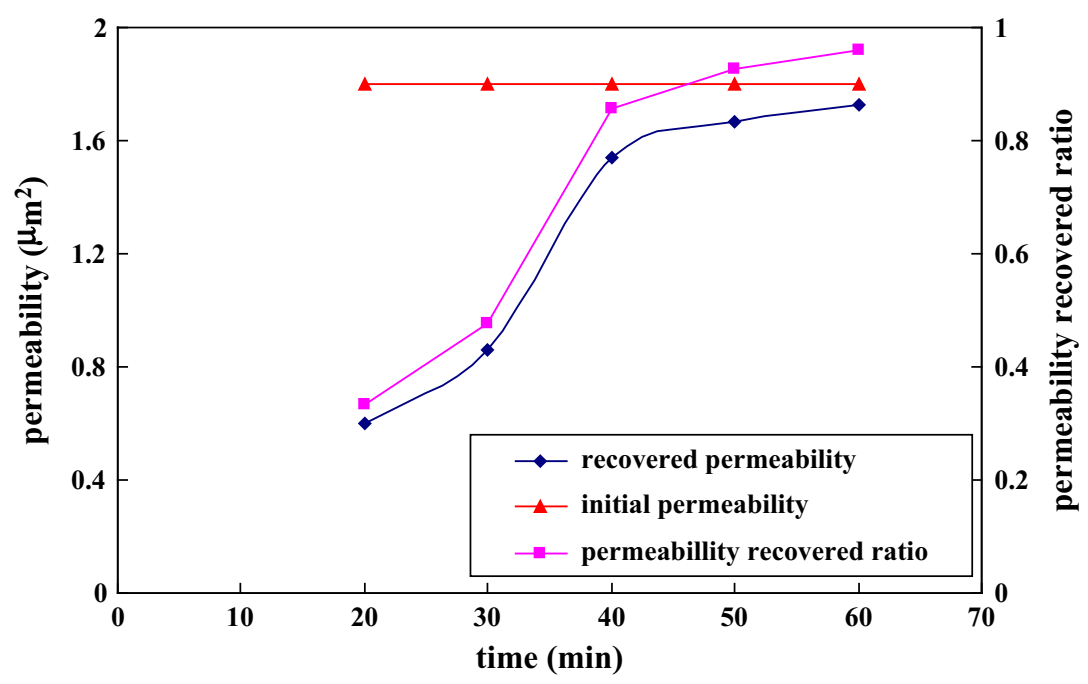

micro bubble treatment fluid is 227 cubic meters. The treatment resulted in a cumulative oil increment of $12,435 \mathrm{t}$ and the average water cut had decreased by $17.6 \%$. The effects of increasing oil production and reducing aquifer yield were obvious.

\section{Case study of Well NP23-X2409}

Well NP23-X2409 is located at Nanpu Oilfield. It is put into production on April, 2009. After 1 month, the water cut rise very fast. From Gadolinium neutron water detection curve, it is found that there is channeling between 28 and 30 layers.

The difficulty of channeling technology is that there is the upper water and lower water. The upper oil-water thin interlayer thickness is $5.8 \mathrm{~m}$ and the lower oil-water thin interlayer thickness is $1.0 \mathrm{~m}$. We cannot use the special pipe string to complete channeling field experiment. At the same time, there is leakage layer between the upper oilwater thin interlayer and the lower oil-water thin interlayer that its absorbability is bigger. If channeling technology is used, it is possible to pollute formation.

To solve these difficulties micro bubble treatment fluid is injected to protect the formation and decrease formation leakage.

Fuzzy-ball micro bubble treatment fluid was applied on well NP23-X2409 on June 2009. About 56 cubic meter micro bubble treatment fluid was injected. Pump pressure is controllable and under ten MPa.

After injecting micro bubble treatment fluid, it is found that the result is effective. Oil production per day increases from 4.5 to 26.8 tons and its water cut decreases from 89.6 to $15.8 \%$. The cumulative quantity of oil was $6176 \mathrm{t}$; the cumulative decreased quantity of water was 3575 cubic meters. The field application of new fuzzy-ball micro bubble treatment fluid indicates that it not only can reduce the operating risk but also has good plug channeling and layer protecting effect.

\section{Conclusions}

The new fuzzy-ball micro bubble treatment fluid is composed of gas bag and fuzzy-ball. The gas bag is composed of gas core, surface tension reducing membrane, high viscosity layer and high viscosity layer fixing membrane. There is fuzzy-ball under the interaction between compatibility enhancing membrane and concentration transition layer of polymer and surfactant. Because of gas bag and fuzzy-ball combination and separation in different environments, the new treatment fluid has unique strong shear thinning and blocking feature.

The new fuzzy-ball micro bubble treatment fluid results in little damage to formation and easy to flow back. After using this treatment fluid, oil well production is recovered quickly.

The field application of new fuzzy-ball micro bubble treatment fluid indicates that it not only can reduce the operating risk but also has good plug channeling and layer protecting effect.

It is shown that it is useful for oil well water shut-off operation. The effect of increasing oil production and reducing aquifer yield is obvious and the period of validity is longer.

Open Access This article is distributed under the terms of the Creative Commons Attribution 4.0 International License (http:// creativecommons.org/licenses/by/4.0/), which permits unrestricted use, distribution, and reproduction in any medium, provided you give appropriate credit to the original author(s) and the source, provide a link to the Creative Commons license, and indicate if changes were made. 


\section{Reference}

Abbasy I, Vasquez J, Eoff L, Dalrymple D (2008) Laboratory evaluation of water swellable materials for fracture shut off. Paper SPE 111492 presented at the SPE North Africa technical conference and exhibition, Marrakech, Morocco. doi:10.2118/ 111492-MS

Eoff L, Dalrymple D, Everett D, Vasquez J (2007) Worldwide field applications of polymeric gel system for conformance applications. SPE production \& operations 22(2):231-235. SPE 98119-PA. doi:10.2118/98119-PA

Hernandez RP, Vasquez J, Cancino V, Soriano E, Halliburton (2010) Successful Water-shutoff case histories in a naturally fractured carbonate reservoir in offshore Mexico using an organically crosslinked polymer system with a modified tail-in. Paper SPE 127981 presented at the SPE International Symposium and Exhibition on Formation Damage Control held in Lafayette, Louisiana

Lane RH, Sanders GS. Water shutoff through fullbore placement of polymer gel in faulted and in hydraulically fractured producers of the Prudhoe Bay field. In: Paper SPE 29475 presented at the 1995 SPE production operations symposium, Oklahoma City

Mercado M, Acuna J, Vasquez J, Caballero C, Soriano E. Successful field application of a high temperature conformance polymer in Mexico. In: Paper SPE 112143 presented at 2009 European Formation Damage, Scheveningen, Netherlands

Seright RS, Liang JA. Survey of field applications of gel treatments for water shutoff. In: Paper SPE 26991 presented at the 1994 SPE III Latin American \& Caribbean Petroleum Engineering Conference, Buenos Aires, Argentina

Van Eijden J et al (2004) Gel-Cement, a water shut-off system: qualification in a Syrian field. In: Paper SPE 88765 presented at the Abu Dhabi international petroleum conference and exhibition, Abu Dhabi. doi:10.2118/88765-MS

Van Eijden J, Arkesteijn F, van Batenburg D, van Vliet J (2005) Development and field application of a shallow perforation shut off system for HP-HT oil wells. In: Paper SPE 94518 presented at the SPE European formation damage conference, Scheveningen, The Netherlands. doi:10.2118/94518-MS 